\title{
RESUMEN
}

En este artículo el P. La Dany SJ, fundador y redactor jefe de la "China News Analysis", trata de los medios de comunicación social en China.

Durante la „Revolución Cultural“, los militares se han apoderado de la Radio y Prensa. Los consideran indispensables para su gobierno. No ahorran medios económicos para su difusión. Cada Provincia cuenta con su propia estación transmisora. En los poblados, donde la gente es analfabeta, instalan altavoces en las plazas, que glorifican a Mao y sus sentencias hasta la sociedad. La producción de transistores aumenta constantemente. Estan al alcance de todos.

La población china que, después de 17 años de experiencia, no cree ni al la prensa ni a la radio, ansía escuchar emisiones extranjeras. Quieren saber la verdad de lo que sucede en el mundo. A escondidas escuchan, por este orden: "The voice of America ", la BBC, Radio Taiwan y Rusia. No menos escuchada es una radio evangélica radicada en las Filipinas, la FEBC.

La situación de los cristianos chinos es desesperade: no tienen reuniones, carecen de libros, en ambiente pagano, sin apoyo para la fe ni aún en la propia familia. Los 3 millones de católicos y los dos de protestantes viven en un desierto espiritual. No obstante, esta misma situación hace que, muchos de los que consiguen huir a Hong Kong, se conviertan, cosa que no hubieran soñado hacer en China, en circunstancias normales. $Y$, en el mismo continente, chino, la juventud comprendida entre los 17 y 18 años, empieza a dudar también de la doctrina oficial.

$\mathrm{La}$ expectación religiosa, un cierto mesianismo, no falta. Como no puede entrar en el país ni literatura religiosa, ni misioneros, la única via de acceso son las ondas de la Radio. Se necesitan muchas y buenas transmisiones, especialmente durante la noche y de madrugada. Se necesitan especialistas, láicos sobre todo, que conozcan a la perfeción la cultura y costumbres chinas. Los programas deben prescindir de toda política, aún del comunismo. Con amenidad y variedad, deben ser portadoras de ayuda espiritual y moral a cristianos y los que no lo son.

Este trabajo debe realizarse de cara al futuro. La situación política se muda continuamente. Para cada situación habría que tener el personal adecuado.

En resumen: la predicación del Evangelio a un cuarto de la humanidad, China, solo puede realizarse hoy mediante la Radio.

\section{Entwurf zu einer Religionspublizistik}

\author{
von Henk Prakke und Gerhard E. Stoll
}

Weil die Wissenschaft von der Publizistik als Lehre öffentlichen Zwiegesprächs in der Gesellschaft alle Bereiche zwischenmenschlicher Kommunikation erkennt, befindet sich publizistische Aussage religiösen Inhalts innerhalb ihres Horizonts. Im Zuge der Erweiterung der fachwissenschaftlichen Fragestellung hat sich $\mathbf{z w i n g e n d ~ d i e ~}$

Dr. Gerhard E. Stoll ist Chefredakteur des evangelischen Wochenblattes "Unsere Kirche* (Bielefeld) und Lehrbeauftragter für Publizistik unter besonderer Berücksichtigung der religiösen Publizistik an der Universität Münster/Westf. 
Aufgabe eingestellt, die Grundströmungen der geistigen Kräfte auszuloten, die das öffentliche Bewußtsein in der Gesellschaft mit Hilfe publizistischen Geschehens mitbestimmen. Dazu gehört zwangsläufig die publizistische Manifestation des Religiösen, die Frage nämlich nach der öffentlichen Intention, Darstellung und Wirkung letzter gesellschaftsprägender Axiome. Publizistische Aussage ist auf eine zugrunde liegende Gesinnung beziehbar, die sich letztlich als weltanschaulich-ideologisch-religiös verwurzelt erweist. Religiöse communio wird zur öffentlichen communicatio.

Die Erforschung und Beschreibung der religiösen Determinante im publizistischen Geschehen hätte sich die „Religionspublizistik“ zur Aufgabe zu stellen. Sie will die öffentliche Kommunikation zeitbezogener, religiöser, konfessioneller, bekenntnisgebundener Erfahrung in der Gesellschaft erforschen. Die „Erfahrung des Heiligen “ und deren Wirkung auf das gesellschaftliche $Z$ wiegespräch manifestiert sich wechselseitig bezogen, in der religiösen Bedingtheit publizistischer Aussage und in der publizistischen Bedingtheit religiöser Aussage. Mit diesem erkenntnistheoretischen Ansatz folgt die Publizistikwissenschaft vergleichbaren Bemühungen der allgemeinen Religionswissenschaft, der Religionspsychologie, der Religionspädagogik und der Religionssoziologie, die sich jeweils in ihrem Wissenschaftsbereich als legitime Spezialgebiete etabliert haben.

Seit der Frühzeit menschlicher Vergesellschaftung ist das Religiöse ein tragendes Element sozialen Bewußtseins und öffentlichen Meinens. Eine Gleichstellung der Volksmeinung mit der Stimme Gottes ist etwa in den Versen der Odyssee erkennbar. Zuvor aber ist in der Mythologie aller Kulturbereiche der Wechselbezug zwischen dem Verhalten der Gruppe als Gesinnungsgemeinschaft und der Artikulierung des Numinosen nachzuweisen. In der Literatur des Alten Testaments sind Religiosität, öffentliche Rede und daraus abgeleitetes politisches Handeln aufs engste verwoben. Die apriorisch für wahr gehaltenen religiösen Uberzeugungen wirken sich in allen Bereichen publizistischen Geschehens aus. Religiöse Symbole werden zu publizistischen "Zeichen" und Kennmarken. Aussagen religiöser Gedanken reihen sich zu Gedankenketten oder Ideenkomplexen und bilden religiöse Systeme, die sich mannigfaltig in publizistischer Demonstration darstellen, sich räumlich objektivieren (Kultplatz als öffentliche Versammlungs- und Redestelle), sich institutionalisieren und kanonisieren (heilige Schriften als Kommunikationsmittel öffentlicher Religiosität) und in den einzelnen Kulturkreisen in ein publizistisches Aussagetun einmünden, um schließlich durch neue religiöse Impulse verwandelt zu werden, wodurch neue öffentliche Bewußtseinsinhalte entstehen.

Eine religiöse Grundlage und Instrumentierung publizistischer Aussage ist mithin essentiell für $z$ wischenmenschliche Kommunikation. Zugleich ist festzuhalten, daß sich Religions- und Glaubensgemeinschaften regelmäßig publizistisch wirksamer Aussagemittel bedienen, um ihr Bewußtsein, Verhalten und Handeln missionarisch werbend, konfirmierend und rechtfertigend darzustellen, Wille zur Publizität wohnt religiösem Geschehen und Handeln wesensgemäß inne. Bei all dem wird sich die Publizistik nicht mit dem Wesen des Religiösen zu beschäftigen haben, sondern mit den publizistischen „Bedingungen und Wirkungen einer bestimmten Art von Gemeinschaftshandeln ${ }^{\star}$, wie es Max Weber für die Religionssoziologie formuliert hat. Mithin sind die innerweltlich vorfindlichen Verhaltens- und Bewußtseinsstrukturen in ihrer publizistischen Relevanz zu prüfen.

Im Ablauf solcher publizistischer Prozesse ist ein Funktionsabtausch zwischen religiösem und säkulärem Verständnis der Inhalte, ein immerwährender Wandel, zu beobachten. Religiös konzipierte Bewußtseinsinhalte verwandeln sich im Verlaufe 
publizistischer Präsentation zu säkularem Verständnis und können wieder zu religiöser Überhöhung zurückgeführt, bisweilen ideologisiert werden (zum Beispiel: Heil in Christus - Heil Hitler - rassische Heilslehre). Entsprechend sind religiöse Elemente im publizistischen Funktionsablauf in verschiedenen Konsistenzgraden, sowohl exorbitant wie auch überdeckt immanent vorhanden.

Im Sinne konzentrischer Kreise ist vom großen zum kleinen Radius hin zu unterscheiden zwischen 1. säkularisierter Religionspublizistik (Ideologie), Einebnung der Religiosität im Säkularismus, (i. e. Horoskope) - 2. allgemein religiöse Publizistik (Mythos, Symbole, i. e. Reden zum Volkstrauertag); 3. bekenntnisorientierte Publizistik (dogmatische und frömmigkeitstypische Stereotypen, i. e. religiöser Film); 4. kirchlich-institutionelle Publizistik (organisierte religiöse Interessenvertretung, i. e. konfessionelle Presse).

Eine Geschichte der religiösen Publizistik wurde noch nicht geschrieben. Einige Daten mögen historische Merkmale aufweisen. Im griechischen, römischen und frühchristlichen Bereich hat die Rolle des Religiösen für das Selbstverständnis der Gesellschaft bis hin zum Staatskult eine erhebliche Bedeutung. Volkstribune mit missionarischem Eifer bedienen sich der Kunst der Rhetorik; Augustin und andere entwickeln auf Grund der rhetorischen Regeln die christliche Homiletik. Im Mittelalter beherrscht religiöse Publizistik weithin die öffentliche Szene. Von ihrem Anbeginn steht die Druckkunst mit beweglichen Lettern im Dienste der Verbreitung zeitbezogenen religiösen Gedankengutes. Die Reformation Martin Luthers ist ohne das publizistische Mittel der aktuellen Flugschrift mit religiösen Inhalten nicht vorstellbar. Theologische Zeitschriften gehören zu den frühesten Beispielen der Zeitschriftenpresse. Die "Monatsgespräche des Christian Thomasius“ etwa propagieren bei allem polemischen und amüsanten Stil den Hallenser Pietismus im Kampf gegen die Orthodoxie. Im Zeitalter der Aufklärung ist eine allmählich säkularisierte Religionspublizistik zu beobachten. Im 19. Jahrhundert treten konfessionelle Gruppen als politische Uberzeugungsträger auf (katholischer Eos-Kreis in Bayern), danach in Verbindung mit der Parteipolitik (Zentrumspresse). Die Einflußnahme der Religionsgemeinschaften auf moderne Kommunikationsmittel ist in der religiös multiformen Gesellschaft der Gegenwart als legitim akzeptiert; konfessionelle Gruppierungen organisieren eigenständige Kommunikationsinstrumente (etwa: Lutherischer Afrikasender "Stimme des Evangeliums“, Addis Abeba). Das zweite Vatikanische Konzil setzt sich in einem besonderen Dekret mit den „Mitteln der sozialen Kommunikation" auseinander.

Der ganze Katalog körperlicher, geistiger und technischer Mittel der Aussage ist grundsätzlich auch auf die Religionspublizistik anwendbar: Im Bereich der originären Publizistik sind religiöse Zeichen $z u$ finden, etwa der heilige Gegenstand (Stein, Baum), das Symbol (Kreuz, Fetisch, Fahne). Der Schall wird zu religiöser Publizistik genutzt (Glodke, Posaune). Die Rhetorik wird in öffentlicher Predigt, Evangelisation, im Ruf vom Minarett geibt. Das Wort schlechthin wird in Zauberformel, Eid, Beschwörung, Mythos, Ritus und Liturgie benutzt. Die religiöse Veranstaltung in Versammlung, Feier und Demonstration folgt publizistischen Formen der Aussage. Im intermediären publizistischen Bereich bedient sich die religiöse Aussage der Presse durch Maueranschlag, Flugblatt, Flugschrift, Zeitung und Zeitschrift, Schriftenreihe, Broschüre und Buch. Das veröffentlichte Bild ist religiös relevant als Ikone, Werbeplakat oder Foto mit religiösen Inhalten. Der Film eignet sich zur Darstellung religiöser Inhalte; Hör- und Sehfunk haben spezifische Interpretationsformen religiöser Aussagen entwickelt. Mysterienspiele und Kirchen- 
kabaretts versuchen auf ihre Weise, religiöse Inhalte darzustellen. Das religiöse Lied einschließlich des missionarischen Kampfliedes ist ein wichtiges religiöses Beeinflussungsmittel.

Die publizistische Fachwissenschaft hat sich gelegentlich mit dem Problem religiöser Publizistik beschäftigt. Schon Caspar von Stieler hat 1697 im dritten Kapitel des ersten Buches „Zeitungs Lust und Nutz“ formuliert: „Der allerhöchste Gott selber ist der erste Zeitungsverkünder gewesen und nachgehend seine heiligen Zeitungsträger: Die Profeten im Alten; und die Apostel im Neuen Testament erwiesen hat, daß er die Zeitungen liebe, wert halte und sie durch die ganze Welt ausgestreut wissen wolle." Franz Adam Löffler, der 1837 den Begriff der Presse als des "Gedankenhandels" auch auf die nichtverbale Kommunikation bezogen hat ${ }^{1}$, wollte auch das christliche Traktat in die fachwissenschaftliche Erörterung einbezogen sehen. Walter Hagemann hat in seinen "Grundzügen der Publizistik"2 der Religion als einem "Grenzgebiet der Aussage" ein eigenes Kapitel gewidmet. Bei einer internationalen Werkwoche katholischer Publizisten 1948 haben sich Emil Dovifat und Walter Hagemann mit Begriff, Aufgabe und Praxis katholischer und christlicher Publizistik befaßt. ${ }^{3} \mathrm{H}$. J. Prakke hat sich als erster ausführlich mit dem Phänomen religiöser Publizistik auseinandergesetzt, den Begriff der "Kerkespraak ${ }^{{ }_{4}}$ untersucht und die Kirche als Kommunikator in seiner Arbeit „De Samenspraak in onze Samenleving" beschrieben. ${ }^{5}$ An amerikanischen Universitäten gibt es ausgeführte Studienpläne für "Religious Journalism"; die amerikanische Kommunikationsforschung beschäftigt sich eingehend mit dem kommunikativen Geschehen bei bekenntnisgebundener öffentlicher Aussage. Amerikanische Kirchengemeinschaften befassen sich systematisch mit der Anwendung der Vertrauenswerbung (Public relations) für religiöse Werbung.

\section{Anmerkungen:}

1. Franz Adam Löffler: Über die Gesetzgebung der Presse. Leipzig 1837.

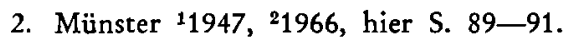

3. Emil Dovifat: Begriff und Aufgabe der katholischen Publizistik heute, und Walter Hagemann: Zur Praxis christlicher Publizistik, in: Heinrich Jansen-Cron, Karl Bringmann (Hrsg.): Katholisches Leben und publizistische Verantwortung, Heidelberg 1949, S. $88-121$.

4. H. J. Prakke: Kerkgang om nieuws, Assen 1955

5. Assen 1957, S. 108-117.

\section{S U M M A R Y}

Communication as a field of scientific inquiry is systematically engaged in formulating in rigorous fashion the principles by which information is transmitted and opinions and attitudes are formed in pervasive communication processes. Research in religious communication is primarily interested in men and media, institutions and channels, the pattern of interactive networks in religious systems. It looks for the consequences of processes of religious communication for prevailing sentiments, definitions of situations and action. The scientists are trying to find an approach to communicative aspects of religious expression adapted to individual and group circumstances, their socially sanctioned values and goals in secular life and their underlying religious philosophy, both in history and today. 


\title{
Nabor Urbain A. De Volder O.F.M. †
}

\author{
von Henk Prakke
}

Löwen (richtig: Leuven) - das war für uns: Professor Pater DeVolder. ,War‘ ... denn am 30. November 1967 ist der hochgeschätzte Gründer des Zentrums für Kommunikationswissenschaften an der Löwener Universität - selbst ein bedeutender Publizistikwissenschaftler - im Alter von 58 Jahren gestorben. Nach einem eindrucksvollen und stark besuchten Trauergottesdienst in der dortigen St. Michaelskirche haben wir uns am 5. Dezember auf dem Minoritenfriedhof zu Vaalbeek von ihm verabschiedet. Seine vier wissenschaftlichen Assistenten trugen die Bahre zu seiner letzten Ruhestätte.

DeVolder wurde am 22. Februar 1909 im flämischen Wakken geboren, machte seine Humaniora bei den Franziskanern in Lokeren, wurde 1934 zum Priester geweiht. Er studierte Philosophie und Theologie in Reken und St.-Truiden und politische und soziale Wissenschaften an der Universität Leuven. Mit einer Dissertation über die Ethik der Arbeit [Ethiek van de Arbeid] promovierte er daselbst im Jahre 1942, anregend begleitet von seinem Doktorvater Pofessor M. J. Leclerca, dessen wissenschaftlicher Assistent er auch war. Nach dem Kriege erhielt DeVolder selbst die venia legendi; seitdem war er der eigenen Alma Mater lehrend und forschend verbunden: 1945 - 1953 als Lektor; 1953 - 1967 als Extraordinarius; 1967 als Ordinarius.

Anfangs las er über Religionssoziologie, Arbeitsethik und Sozialgeschichte. Sein prüfender Geist wandte sich dabei immer mehr den zentralen Fragen der gesellschaftlichen Kommunikation $\mathrm{zu}$, und $\mathrm{zwar}$ besonders auf dem Gebiet von Presse und Gesellschaft. Schon 1947 gründete er an der Universität ein eigenes ,Instituut voor Journalistiek'. Dieses Interesse führte ihn dann auf eine Studienreise nach Amerika, worüber er in seiner Abhandlung, Journalisme en Opvoeding in de Verenigde Staten' 1950 berichtete. Seitdem hat er mit großer Energie (mit übermenschlicher Überwindung trotz immer stärkerer gesundheitlicher Beschwerden) versucht, nach amerikanischem Vorbild auch in seinem Institut eine fachgerechte Journalistenausbildung zu verknüpfen mit einer akademischen Bildung, die sich besonders für wissenschaftliche Erforschung sozialkommunikativer Phänomene und Vorgänge einsetzt. Im Zuge dieser Entwicklung wurde das Institut 1961 umgewandelt in das heutige ,Centrum voor Communicatiewetenschappen' (,Ce-Co-We'), das 1964 die schönen Räume an der Van Evenstraat bezog. Nicht weniger als elf Dozenten sind diesem akademischen Zentrum verbunden; sie behandeln u. a. die Fächer Kommunikationswissenschaft, Soziologie der Presse, Pressegeschichte, Presse-Technik, Kommunikationsrecht, Darstellende Künste und audiovisuelle Medien, Filmgeschichte, Sozialpsychologie und Ästhetik des Films, Film-Technik, Produktionsprozesse in Hörfunk und Fernsehen, Wortsendungen in Hörfunk und Fernsehen, Literaturwis-

Prof. Dr. Henk Prakke (Meppen-Zweeloo/Niederlande) ist Direktor des Instituts für Publizistik der Universität Münster. 
senschaft, Musik in audiovisuellen Produktionen, Public Relations, Offentliche Meinung, Propaganda.

Wie sehr auch Organisations- und Verwaltungsfragen ihn beschäftigten, Hauptaufgabe blieb für DeVolder seine eigentliche Dozentenarbeit in Ausbildung und Bildung seiner Studenten. Als Doktorvater führte er eine Reihe von Kandidaten der Religionssoziologie zum Doktorat. Für die Kommunikationswissenschaften fing dies erst an; es promovierten bislang: Dr. G. Fauconnier mit einer Dissertation über "Struktuur, werking en organisatie van het reclamebedrijf in Belgie ${ }^{\alpha}$ (1962) und Dr. L. Boone (auch jetzt noch Assistent im ,Ce-Co-We') über „De sociaalpolitieke betekenis van de Radio-berichtgeving " (1966).

Von DeVolders eigenen Veröffentlichungen seien hier besonders die Bücher „De Ethiek van de Pers" (1952), "De Communistische Propaganda" (1957) und die deutschsprachige "Soziologie der Zeitung" (1959, - Bearbeitung eines Teiles des erstgenannten Buches) genannt. Sie bekunden alle den breit-informierten, scharfbeobachtenden, systematisch darlegenden Wissenschaftler. DeVolders soziologische Einstellung führte ihn dazu, die Presse und ihre Problematik immer in ihrer gesellschaftlichen Umrahmung zu verstehen zu versuchen. Damit hat er nicht nur für die Presse-Ethik Pionierarbeit geleistet (uns fehlt im deutschen Sprachbereich noch immer eine Ethik der Publizistik überhaupt), sondern auch die altehrwürdigen Presse,Kriterien' der Zeitungswissenschaft als soziale Funktionen erkannt. Damit wurde er zugleich einer der Wegbereiter für die Funktionale Publizistikwissenschaft. Für mich kulminiert dies in seinem wesentlichen Beitrag zum besseren Verständnis des für die Publizistik so wichtigen Begriffs der Aktualität. DeVolder liebte es, neue Wege zu gehen, und - ihm gelang es. Er war ein origineller Denker. Eine Sammlung seiner zerstreuten Aufsätze auf kommunikationswissenschaftlichem Gebiet (wer kennt sie alle?) wäre nicht nur ein Akt der Pietät, sondern auch die Erschließung einer weiteren Fundgrube DeVolderscher Gedanken.

DeVolder ist - nach menschlichem Maßstab - zu früh von seinem Posten abberufen worden; sein wissenschaftlicher Nachwuchs - Dr. Luk Boone, Lic. Hendriks, Lic. Van der Biesen, Lic. Van Pelt - brauchte ihn noch. In Deutschland hatte er besonders enge Verbindung mit dem Institut für Zeitungsforschung in Dortmund (wo die Ubersetzung seines Buches über die Soziologie der Zeitung besorgt wurde) und mit meinem Institut in Münster. Noch im vergangenen April war ich bei ihm und seinen Studenten zu Gast für einen Vortrag mit Diskussion. Auch wir werden den humanen Gelehrten und den geselligen Gastgeber vermissen.

Demgegenüber formulierte es einer am Tage der Beerdigung so: Es wird Freude geben im Himmel über einen, der heimkehrt, nachdem er seinen irdischen Auftrag so gut erfüllt hat. 